\title{
Role played by Italy in the history of syphilis
}

\author{
M A WAUGH \\ From the Department of Genitourinary Medicine, General Infirmary, Leeds
}

\section{Introduction}

Despite dissenting views on the origin of the wellrecorded outbreak of syphilis in the Italian peninsula towards the end of the fifteenth century, there is no disputing the importance of Italian culture and medicine in the development of the history of syphilis. In the earlier part of this century most of the detailed work on the subject was recorded by medical historians of the German School. Bloch ${ }^{1}$ was the chief supporter of the theory of the Columbian origin of syphilis. Sudhoff, ${ }^{2}$ while making no dogmatic assertion about the origin, was the principal collator of early sources in European literature, showing the intimate connection between the contemporary life of Italy, Spain, and Germany.

\section{Origin of syphilis in Europe}

The followers of the Columbian theory of the origin of syphilis do not consider that syphilis existed in western Europe before 1493, its advent coinciding with the return of Columbus, a Genoan, and his crew after the discovery of the New World.

This view is opposed, however, by the followers of the unitarian concept of the treponematoses such as Hudson. ${ }^{3}$ This concept emphasises the evolutionary relationship of yaws, pinta, endemic syphilis, and sporadic syphilis, regarding them all as varieties or syndromes of one disease caused by one parasite, the Treponema pallidum. This concept considers subSaharan Africa to be the area for the origin of treponematosis.

The unitarian theory explains the epidemic in Europe at the end of the fifteenth century in two alternative ways. Firstly, the disease could have existed in some mild form in Europe for centuries, the organism suddenly developing a new and deadly virulence. ${ }^{4}$ Secondly, the epidemic may have stemmed from an alteration in the organism of yaws, which had been brought back to Spain and Portugal by travellers.

Address for reprints: Dr M A Waugh, Department of Genitourinary Medicine, General Infirmary, Great George Street, Leeds LS1 3EX

Accepted for publication 25 August 1981
Syphilis is usually said to have first appeared at the $e^{\mathscr{D}}$ Siege of Naples in 1494-95, but Caspare Torella, ${ }^{5}$ a $\vec{\circ}$ Spanish physician to Pope Alexander VI, stated that $\overrightarrow{\vec{\omega}}$ it was known in Avignon in 1493. There was $a_{\odot}^{\omega}$ concept of a disease like syphilis which was distinct $\stackrel{\text { ? }}{=}$. from leprosy and chronic skin disease in Provence ${ }_{0}$ for a considerable period, perhaps explaining the term 'mal franzoso'. Some authors ${ }^{2}$ have thought 0 that scabies grossa, mentioned in Italy as early as the ${ }^{N}$ thirteenth century and treated with mercury, could have been syphilis.

There is even a problem in dating the Siege of Naples. Charles VIII of France claimed the throne of Naples from Ferdinand II. At that time the $\vec{\varnothing}$ Gregorian calendar was used in Italy, and Naples was! besieged by the French from 21 February 1495. According to the French calendar the date was 1494, 五 as the year began at Easter (19 April). Gabriele Fallopius ${ }^{6}(1523-62)$ related in 1563 that the harlots were driven out to the welcoming arms of the $\frac{\mathbb{Q}}{\mathbb{Q}}$ besiegers and before long the French army had to $\stackrel{2}{\vec{P}}$ withdraw, being stricken with the Neapolitan disease, $\frac{}{3}$ from whence it spread all over Europe. Like so much that followed in the history of venereal diseases, it is often difficult to unravel what in fact did happen; different authors interpret differently and often add: to and even exaggerate the pattern of events.

\section{Early writers on syphilis in Italy}

In the last few years of the fifteenth century several 음 writers in Italy described syphilis. Niccolo Leoniceno of Vicenza ${ }^{7}$ (1428-1524), professor of medicine at Ferrara, wrote a pamphlet in conjunction with the N humanist, Aldus Manutius, of Venice in June 1497, in which he described the disease and included its differential diagnosis. Leoniceno stated that there $\omega$ had been accounts of a similar disease as early as Hippocrates, in whose Aphorisms (book 3, chaptero $\mathrm{XX})$ it is mentioned, 'that in the summer ulceration of the mouth, skin eruptions, and mortification of ${ }^{+}$ the privy parts occurs'.

Torella wrote two important works on syphilis in November 1497 and between 1499 and 1500 . In the first, ${ }^{5}$ he called the new disease 'pudendagra' and $\varnothing$ gave a description of how a patient caught the 
affliction in the month of August. It started with an indurated ulcer on the penis and enlargement of the inguinal glands, followed later by pains in the head, shoulders, breast bone, arms, legs, and ribs and then by multiple pustules on the head, face, and chest 10 days later. Thus, he was the first to describe the chancre, related lymphadenopathy, osteoscopic pains, and the secondary eruption. It may be that Torella's subject was the notorious Cesare Borgia (1476-1507), the son of Alexander VI, who was made a cardinal at the age of 15 in 1492, which would have made him 20 at the time of Torella's description. Torella described five cases; he alluded to divine wrath as the cause and relied on mercurial ointment for treatment. In his second work $^{8}(1499-1500)$ he described how healthy infants could be infected from breast sores of a syphilitic wet nurse and how one nurse could contaminate a great number of suckling babes.

Corradino Gilino, ${ }^{9}$ probably a pupil of Leoniceno at Ferrara, recommended (1497) more use of mercurial inunction, adding sublimate of mercury to mercury in metallic form, although later he retracted this idea, restricting sublimate to washes and fomentations. He advised against too much blood letting, although he favoured the rather gruesome therapy of applications of a red-hot iron to the head in the region of the coronal sulcus, thinking thereby to influence the pituitary, the source of phlegm.

Natale Montesaûro of Verona ${ }^{10}(1498)$ wrote his Tractate as much to attack Leoniceno as to describe syphilis. He stated he had long been familiar with the disease, and he probably gave a better description of pains in the long bones than Torella. Unlike the latter, he discounted mercury but stated that he had seen cases of the disease without any primary infection of the genitals.

The last of the medical writers from Italy in the short period before the end of the fifteenth century was Antonio Scanaroli of Modena ${ }^{11}$ (1480-1517). He supported Leoniceno, but made the peculiar statement that, "the disease is not passed only through intercourse, but could arise de novo'. He alluded to it occurring in virgins and old men who had no sex life.

The Guicciardini were an important Florentine family and a member of it, Francesco Guicciardini, ${ }^{12}$ who wrote a history of his times from 1494 to 1532 , stated that, 'the physicians understood nothing of the treatment of this disease, and, instead of the appropriate medicines, they frequently gave remedies which were the opposite and capable rather of irritating the disease'.

\section{Sixteenth century descriptions in Italy}

The writings of Antonio Benivenio (1502), a Florentine physician, were published (1507) after his death. ${ }^{13}$ They are remarkable for detailed descriptions of different forms of cutaneous lesions of the disease.

John of Vigo (1514) wrote his great and influential surgical treatise in Rome, in which he included two chapters on the French disease. ${ }^{14}$ Of importance in the clinical description of the disease is the mention of ocular manifestations. Like most others of the time he advocated mercury as treatment in one form or another.

\section{FRACASTORO}

There are several other Italian writers on venereal disease in the first part of the sixteenth century, but none of such importance as Girolamo Fracastoro (1478-1553), a native of Verona, practising in physic. In 1525 Fracastoro had written a poem in Latin hexameters on syphilis, dedicating it to his patron, Cardinal Pietro Bembo. He alluded to mercury from Mount Etna but after some criticism was persuaded to change the poem somewhat to exclude mercury, then out of favour, and include references to guaiacum, which was by then in vogue for the treatment of morbus Gallicus. The work, Syphilis sive Morbus Gallicus, ${ }^{15}$ was published in a small quarto of 36 pages in August 1530 and consists of three books. In the first the astrological causes of the new disease are mentioned. Then, two-thirds of the way through, a clinical description of the disease is given. It ends in the classical style of Virgil. The second book again eulogises Bembo. Syphilus makes his entry in line 288 of the third book of 419 lines. The shepherd, Syphilus (though some would suggest 'syphilus' means pig-lover, 'sus' being Homeric Greek and Latin for pig), watched over the flocks of King Alcithous and one day reproached Apollo for parching the trees and draining the springs in such a manner that his flock was dying of want of shade and lack of water. He swore he would in future sacrifice to his king and not to the sun. Outraged, Apollo inflicted a disease so far unknown, which afflicted the whole population, including the king. On the advice of the nymph, Ammerice, the inhabitants offered sacrifices to Juno and Tellus and the latter produced the guaiacum tree which cured the disease. To make absolutely sure, the priests offered Syphilus as a sacrifice to Apollo, but Apollo accepted a bullock instead. The importance of this poem was enormous, not only in giving the disease a name but in being translated into most European languages.

America had been officially recognised in atlases of 1518 and 1524. Guaiacum was indigenous to the West Indies and its importation was a monopoly of the House of Fugger of Augsburg. It had been imported since 1508 , its popularity being assured by Ulrich von Hutten ${ }^{16}$ in his work (1519) De Morbi 
Gallicum Curatione per Adminstrationem ligni Guaiaci. Verona lies at the start of the easiest route over the Alps, by way of the Brenner Pass, and there would have been regular commerce between Verona and southern Germany.

The name syphilis was not used in English until 1686, when the dramatist Nahum Tate ${ }^{17}$ translated Fracastoro's work: the first mention in English medical writing was by Daniel Turner ${ }^{18}$ (1717).

\section{AFTER FRACASTORO}

About the same time as Fracastoro, Niccolo Massa of Venice (1537) wrote a work in five parts on morbus Gallicus. ${ }^{19} \mathrm{He}$ admitted that coitus was the usual cause of the disease, but not the only cause. He described congenital syphilis. Previously he had thought the disease had been contracted by infants who had taken the mother's breast milk, but he was able to show that it had occurred in three children who had not suckled and must thus have been passed in infected blood. He also described the necropsy appearances of syphilis. He should be noted for an early method of prophylaxis, washing the genitals of both men and women after intercourse with a mixture of cold white wine and vinegar. He recommended guaiacum, sarsaparilla, and china root but mercury only with reserve.

Antonio Brassavolus (1551) of Ferrara is noted for dividing morbus Gallicus into 234 types. ${ }^{20} \mathrm{He}$ did, however, mention deep kissing (oscula cum vibratione et conflicto linguarum) as a cause of chancre of the mouth and was among the first to describe anal chancre. He considered gonorrhoea, however, to be part of the great disease of verola (syphilis).

Gabriele Fallopius, a pupil of Vesalius, is not only celebrated for describing the anatomical parts named after him but also for an important posthumous work on syphilis. ${ }^{6} \mathrm{He}$ was an influential exponent of the Columbian theory. He had some interesting ideas on the aetiology of syphilis, noting that men who were circumcised or had the glans exposed were less likely to contract the disease than those who had a long prepuce which easily became injured. He described the course of the disease, and considered an indurated chancre to be pathognomonic. He noticed that syphilis caused alteration to the throat (with roughness of the voice), nocturnal pains, and lesions of the bones and gummata. Although he used mercury by inunction he preferred guaiacum, China root, and sarsaparilla. He gave a good description of phimosis and its cure and described condylomata lata. $\mathrm{He}$ is best remembered as a very early protagonist of the condom, advising those in need to carry one at all times. Like Massa, he also believed in preventive antiseptic measures and described various $\frac{\delta}{\frac{\Phi}{\Phi}}$ remedies.

\section{Eighteenth century advances}

The Italian School waned in the seventeenth century. Giovanni Maria Lancisi of Rome (1654-1720), how-을 ever, was one of its most brilliant lights, leaving science enriched by his many discoveries. Venereology has been especially helped by the second of his two great works, De Motu Cordis et ${ }^{\text {s }}$ Aneurysmatibus ${ }^{21}$ published in 1728 after his death. $\vec{\circ}$ In this work he described Gallic (syphilitic) $\overrightarrow{\vec{\omega}}$ aneurysm, 'it being known not only by the impure ${ }_{\sigma}^{\omega}$ intercourse that has gone before and signs of venereal $\stackrel{5}{?}$ disease that have already spread to other partsis besides, but above all it is identified by the manner in ${ }_{\sim}^{\infty}$ which a definite place is attacked by the aneurysm.' io

Perhaps the founder of modern pathology can $b e_{\circ}^{N}$ considered to be Giovanni Battista Morgagni $(1682-1771)$. He was a pupil of Valsalva and $\vec{\square}$ published his great book ${ }^{22}$ De Sedibus et Causiso Morborum after 60 years of observation and unhurried thought at the age of 79 in 1761, living to $\vec{\circ}$ see several reprints and not dying until his ninetieth? year. The work of Morgagni on aneurysms is probably better than that of Lancisi. He noted that sudden death resulted from rupture of aneurysms $\frac{\partial}{\circ}$ and that they commonly occurred in men whose occupations were susceptible to syphilis, such as $\frac{2}{\propto}$

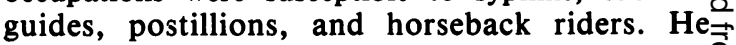
recorded the occurrence of endocarditis after virulent 3 gonorrhoea but unfortunately made no distinction ${ }_{-}$ between gonorrhoea and syphilis, considering lues venerea to be all one disease. He also made the common mistake of the times of attributing to? syphilis all the lesions occurring in the body of a 3 sufferer from that disease, stating that 'the lungs, aorta, kidneys and their appendages are foundO injured in those who have suffered considerably and for a long time with lues venerea.' It is of interest to the medical historian that James Boswell, while travelling in Italy in 1765, consulted Morgagni (then 83) at Padua. The aged physician told him to lead an sober life, stop using the syringe, and to let nature heal itself. ${ }^{23}$ Boswell unfortunately did not heed the warning.

\section{Hypodermic syringe and nineteenth century advances

Syringes have been known in medicine since the earliest times. For purposes of anatomical demon- $-\frac{0}{\mathbb{D}}$ stration Galen injected the cerebral vessels. Leonardo? da Vinci injected the cerebral ventricles with wax, $\varrho$ and Harvey used injections of dye. From time 
immemorial syringes have been used for urethral, vaginal, and rectal irrigation and for the probing and introduction of fluids into sinuses and fistulas.

Hypodermic use, however, does not seem to have come about until the nineteenth century. Alexander Wood (1855) of Edinburgh was among the first to use the syringe for this purpose. Among the first in venereology was Angelo Scarenzio of Pavia, who published a work on the treatment of constitutional syphilis with subcutaneous injections of mercury into the thigh in 1864. There was an immediate improved response in the patients, ${ }^{24} 25$ but unfortunately abscesses often occurred at the sites of injection. Carlo Ambrosoli of Milan ${ }^{26}$ and Berkeley $\mathrm{Hill}^{27}$ in London published similar results. Hebra in Vienna had earlier tried subcutaneous injections but had given them up when too many side effects occurred.

Notable experimental work was carried out by Pietro Pellizzari (1823-92) of Florence, who proved the possibility that syphilis could be transmitted by blood transfusion.28 29 In February 1862 he inoculated blood from the cephalic vein of a women with secondary syphilis on to the arms of three young volunteer doctors. One of them (Bargioni) developed a chancre at the point of inoculation on the left forearm after 22 days as well as axillary lymphadenopathy. It was mentioned that mercury treatment followed, but the final fate of Dr Bargioni is unknown.

History tends to repeat itself. Giuseppe Profeta (1840-1911) wrote on congenital syphilis. ${ }^{30}$ Others have labelled his findings as Profeta's law-that is, the healthy child of a syphilitic mother is immune to syphilis. In fact Profeta was supposed to have implied that the healthy child of a syphilitic mother could be suckled by her or by a syphilitic nurse with impunity. In the light of advances in immunology, which were not to come until the twentieth century, the law rapidly became outdated. ${ }^{31}$ Profeta had not realised that an apparently healthy child could have latent congenital syphilis. The syphilitic infant is often asymptomatic at the time of birth and for the ensuing few weeks. By the late nineteenth century advances into research and the treatment of syphilis no longer seem to have come from Italy; the Germanspeaking countries then made the greatest contribution.

\section{References}

1. Bloch I. Der Ursprung der Syphilis. 1st ed. Jena; Gustav Fischer, 1901.

2. Sudhoff K. The Earliest Printed Literature on Syphilis. Florence: R Lier, 1925.

3. Hudson EH. Treponematosis. Oxford: Oxford University Press, 1946.

4. Hackett CJ. On the origin of the human treponematoses. Bull WHO 1963; 29:7-41.

5. Torella C. Tractatus de Pudendagra seu Morbo Gallico. Rome, 1497.

6. Fallopius G. De Morbo Gallico. Padua: L Gryphium, 1563.

7. Leoniceno N. Libellus de Epidemia quam vulgo Morbum Gallicum vocant. Venice: Aldi Manutii, 1497.

8. Torella C. Dialogus de Dolore cum Tractatu de Ulceribus in Pudendagra evenire solitis. Rome, 1499-1500.

9. Gilino C. De Morbo quem Gallicum noncupant. Ferrara, 1497.

10. Montesauro N. De Dispasitionibus quas Vulgares Mal Franzoso appellant. Verona, 1498.

11. Scanaroli A. Disputatio de Morbo Gallico. Bologna, 1498.

12. Guicciardini F. La Historia d'Italia Vinegia. Presso Giorgio Angelieri, 1583.

13. Benivenio A. De Morbo quem vulgo Gallicum vocant. Florence, 1507.

14. Vigo J. Practiosa Copiosa in Arte Chirurgica. Rome, 1514.

15. Fracastoro G. Syphilis sive Morbus Gallicus. Verona: S Nicolini da Sabbio, 1530.

16. Von Hutten, U. Von der Wunderlichen Arzenei, des Harzes, Guaiacum genannt und Wieman die Franzosen beilen soll. Strasburg, 1519.

17. Tate N. Syphilis or a Poetical History of the French Disease. London: J Tonson, 1686.

18. Turner D. Syphilis. A Practical Dissertation on the Venereal Disease. London, 1717.

19. Massa N. Liber de Morbo Gallico. Venice, 1532.

20. Brassavolus AM. Ferrarensis, de Morbo Gallico. Venice, 1551.

21. Lancisi GM. De Motu Cordis et Aneurysmatibus. Rome: Salvioni, 1728.

22. Morgagni GB. De Sedibus et Causis Morborum. Venice: Remondiniana, 1761.

23. Ober WB. Boswell's Clap and Other Essays. Carbondale and Edwardsville: Southern Illinois University Press, 1979;11.

24. Scarenzio A. Subcutaneous injections of a preparation of mercury against constitutional syphilis. Ann Universali de Med Milano 1864; 189:602.

25. Scarenzio A. Hypodermic injection of calomel in syphilis. $\mathrm{Br}$ Med J 1865; ii: 60.

26. Ambrosoli $\mathrm{C}$. Sul modo di curare in sifilide constituzionale colle iniezioni sottocutane di un preparato di mercurio. Giornale Ital delle Mal Veneree 1866;1:97-116.

27. Hill B. Subcutaneous injection of mercury in constitutional syphilis. Lancet $1866 ; \mathrm{i}: 498$.

28. Pellizzari P. Della Transmissione delle Sifilide Mediante l'Inoculazione del Sangue. Lo Sperimentale. Florence, 1862.

29. Pellizzari P. Successful inoculation of syphilitic blood. Br Med $J$ 1862; i:495-6.

30. Profeta G. Sulla sifilide per allattamento. Sperimentale $1865 ; 15: 328-38,339-418$.

31. Nabarro D. Congenital Syphilis. London: Arnold, 1954:66. 